\title{
$\mathrm{FeS}$ 粉末のパルス通電焼結
}

\author{
堀江和也 ${ }^{1}$ 植田航平 ${ }^{2}$ 南口 \\ ${ }^{1}$ 長岡技術科学大学大学院技学研究院機械創造工学専攻 \\ ${ }^{2}$ 長岡技術科学大学工学部機械創造工学課程
}

J. Japan Inst. Met. Mater. Vol. 82, No. 8 (2018), pp. 277-280

(C) 2018 The Japan Institute of Metals and Materials

\section{Pulsed Electric Current Sintering of FeS Powder}

\author{
Kazuya Horie ${ }^{1}$, Kohei Ueta ${ }^{2}$ and Makoto Nanko ${ }^{1}$ \\ ${ }^{1}$ Department of Mechanical Engineering, Graduate School of Engineering, Nagaoka University of Technology, Nagaoka 940-2188 \\ ${ }^{2}$ Department of Mechanical Engineering, Nagaoka University of Technology, Nagaoka 940-2188
}

\begin{abstract}
Hot hammer forging is a useful manufacturing process for producing mechanical parts with excellent mechanical properties. One of the problems in this forming process is seizure between die and work-piece. It does not only decrease quality of the products and the productivity but also put a worker in danger. In order to avoid the seizure in forging process, sulfonitriding to die surface has been often applied. The surface treatment provides a nitrided zone with a sulfide layer as a top layer. The nitrided zone has higher hardness of the die while the sulfide layer improves anti-seizure ability and decreases the friction coefficient. The sulfide layer on the die surface is constituted of Iron sulfide (FeS). However, mechanical and physical properties of FeS have not been investigated yet. In the present study, pulsed electric current sintering of FeS powder was studied to fabricate dense sintered bodies of bulk FeS for evaluating physical and mechanical properties. Some mechanical properties such as Vickers hardness and fracture toughness of sintered FeS were evaluated in the present report. [doi:10.2320/jinstmet.JBW201710]
\end{abstract}

(Received January 11, 2018; Accepted April 12, 2018; Published June 8, 2018)

Keywords: iron sulfide (FeS), sulfonitriding, pulsed electric current sintering (PECS)

\section{1. 緒言}

工業分野において，鍛造は様々な形状の金型で被加工材を 目的の形状に変形させる加工方法である ${ }^{1,2)}$. この方法によっ て製造される機械部品は様々な優れた特徴を持ち ${ }^{3)}$, 各種製 品製造に利用される ${ }^{4)}$. 熱間ハンマー型鍛造の場合, 高温に 熱した材料と鍛造金型が強固に固着するという，「焼付き」と 呼ばれる問題が発生することがある ${ }^{5-7)}$. これは製品品質や生 産性を著しく低下させるばかりでなく，生産従事者を危険に さらすこともある。これを防ぐために今までにも潤滑剤など 様々な方策がとられており ${ }^{8-10)}$, 金型材料の表面処理も多く 検討されている11). 金型材料の表面処理の一つに浸硫窒化処 理がある ${ }^{12-19)}$. これは, 摩擦係数の低減と耐焼付き性の向上 を目的とした硫化物層と, 金型の硬さ向上や長寿命化を目的 とした窒化層の形成を $500^{\circ} \mathrm{C}$ 程度の高温で処理するものであ る. 浸硫窒化処理における耐摩耗性向上のメカニズムには不 明な面も多い20). したがって, 硫化物層が耐摩耗性などにど のように作用しているかを検討し，明らかにすることはその 応用上で非常に重要である。硫化物層は主に FeS からなるた め, その FeS の物性詳細は欠かせない要素となる。しかしな がら, その FeSの物性がほとんど調査されていないどころか, $\mathrm{FeS}$ の特性を評価するための緻密なバルク体を得る方法も報 告がない. そこで本研究では FeS のパルス通電焼結 (PECS) を試みた。 パルス通電焼結は急速加熱が可能な焼結であり,
不安定な物質の焼結固化に多くの実績がある ${ }^{21,22)}$.

$\mathrm{Ti}$ や $\mathrm{Cu}$ の硫化物は PECS による焼結固化により S 成分の 減少が報告されている ${ }^{23-25)}$. これらの硫化物同様に FeS にお いても, S 成分が減少する可能性がある. 本研究では, FeS の緻密化に加えて, その焼結前後での S 成分の変化に着目し た.

今回, この焼結時の還元を防ぐために窒化ホウ素 $(\mathrm{BN})$ の粉 末の中に埋没させて焼結することを試みた。 BN はその熱的 安定性の高さから, FeS と反応せずに黒鉛型との接触を防止 できると期待できる．また， BN は焼結性が低いため，焼結 後の試料除去も容易である.

\section{2. 実 験 方 法}

Fig. 1 は FeS 焼結体の作製方法の模式図である。市販 FeS 粉末(高純度化学平均粒径 $60 \mu \mathrm{m}$ 純度 $99 \%$ 以上) を乳鉢と, 窒素ガス中でのボールミルで粉砕した後, 直径 $\phi 15 \mathrm{~mm}$, 厚 さ約 $5 \mathrm{~mm}$ で圧粉体を仮成形し，それをPECS 用炭素型内へ 窒化ホウ素粉末(高純度化学 平均粒径 $10 \mu \mathrm{m}$ 純度 $99 \%$ 以上) と一緒に埋没させ, PECS 装置を用いて焼結した。焼結温度 $700,800,900^{\circ} \mathrm{C}$, 昇温速度は到達焼結温度の $100^{\circ} \mathrm{C}$ 手前まで は $100^{\circ} \mathrm{C} / \mathrm{min}, 50^{\circ} \mathrm{C}$ 手前までは $50^{\circ} \mathrm{C} / \mathrm{min}$, その後は $10^{\circ} \mathrm{C} / \mathrm{min}$ で昇温した。焼結圧力 $45 \mathrm{MPa}$, 焼結保持時間 $15 \mathrm{~min}$, 真空 度 $6 \mathrm{~Pa}$ で焼結を行った. 焼結後のバルク体は耐水ペーパーで \#3000までの研摩をケロシンを使用して行った。また，ボー 


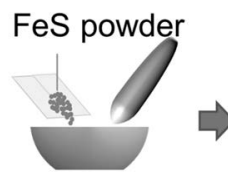

Mortar milling $1 \mathrm{~h}$

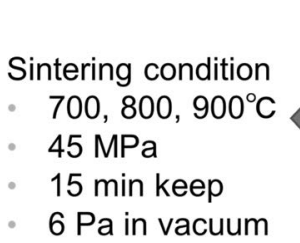

Fig. 1 Schematic illustration of production flow and sintering condition of sintered FeS using PECS.

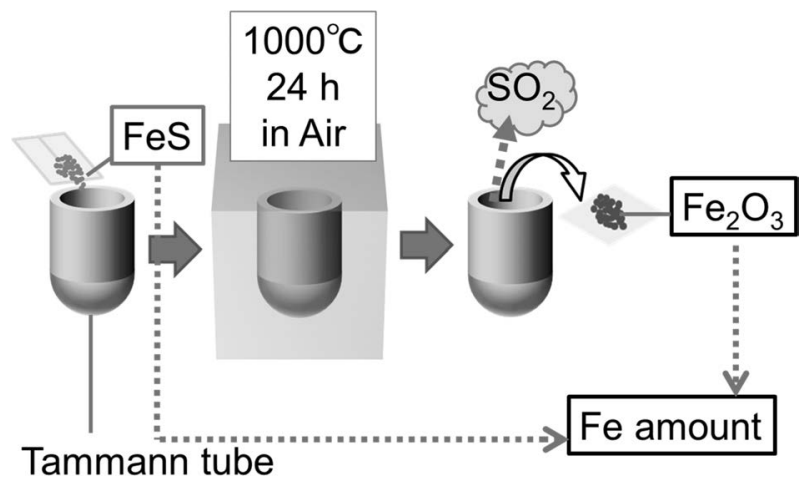

Fig. 2 Schematic illustration of confirmation of stoichiometry of FeS.
ルミル後の $\mathrm{FeS}$ 粉末と焼結後の $\mathrm{FeS}$ バルク体を $\mathrm{X}$ 線回折 (XRD)により相同定を行った。併せて, 焼結前後での FeS の 化学量論組成の確認を行った. Fig. 2 はその手順の模式図で ある. $\mathrm{FeS}$ 粉末の化学量論組成を確認するため, 大気中で $1000^{\circ} \mathrm{C}, 24 \mathrm{~h}$ で酸化処理を行った. $\mathrm{FeS}$ 中の $\mathrm{S}$ は酸化によっ て完全に除去され，タンマン管内には $\mathrm{Fe}_{2} \mathrm{O}_{3}$ のみが残るので, その処理前後の質量を測定することにより, FeS の化学量論 を計算した。また，焼結体の密度測定にはトルエンを用いた アルキメデス法で測定した。硬さは室温でのビッカース硬さ 試験(荷重： $49 \mathrm{~N}$ ，保持時間 $10 \mathrm{~s}$ ) で評価した。破壊勒性值の 測定は Indentation Fracture 法(IF 法)を用いた ${ }^{26)}$. ビッカー 又硬さ試験や破壊勒性值には比較対象として，実際の熱間鍛 造時にワーク材としてよく使用される炭素鋼 $(\mathrm{S} 55 \mathrm{C})$, 酸化皮 膜の主構成となる $\mathrm{FeO}$ を準備した。 なお，鉄酸化物の作製に ついては既報の通りである27).

\section{3. 実 験 結 果}

Fig. 3 はボールミル粉砕後 (焼結前)の FeS 粉末の SEM 像 と XRD パターン, Fig. 4 に $900^{\circ} \mathrm{C}$ 焼結後の $\mathrm{FeS}$ 焼結体の破面 $\mathrm{SEM}$ 像と XRD パターンを示す。ボールミル後 $\mathrm{FeS}$ 粉末のお

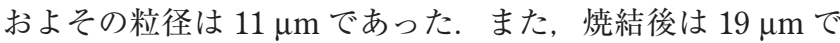
あった，焼結前後で FeS 以外の不純物相は確認されず，焼結

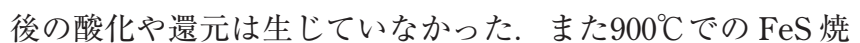

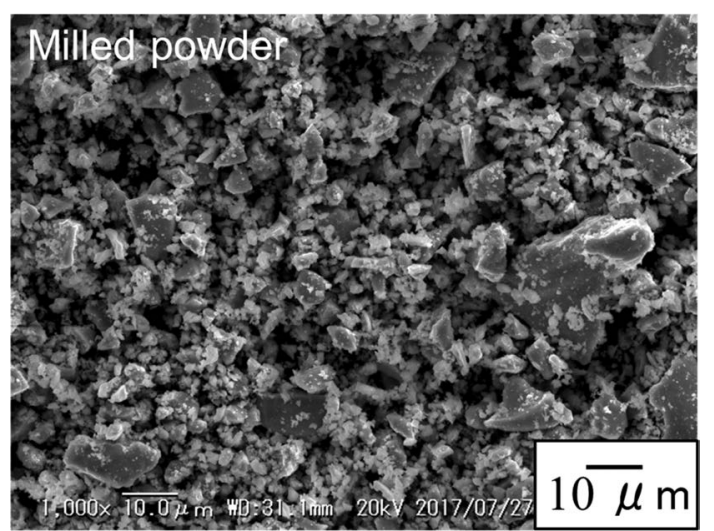

(a) SEM image

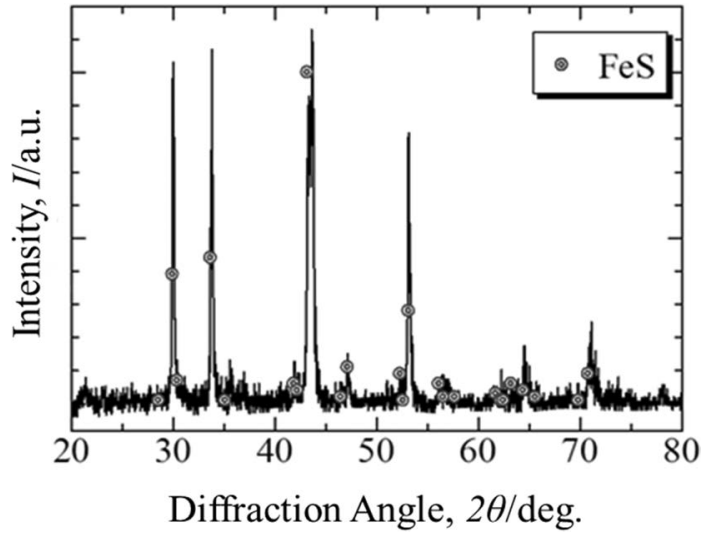

(b) XRD pattern

Fig. 3 SEM image and XRD pattern of FeS powder after ball milling.

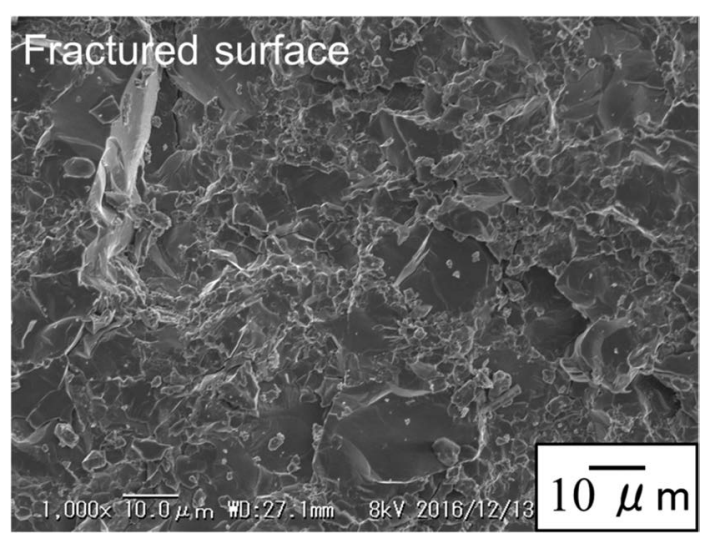

(a) SEM image

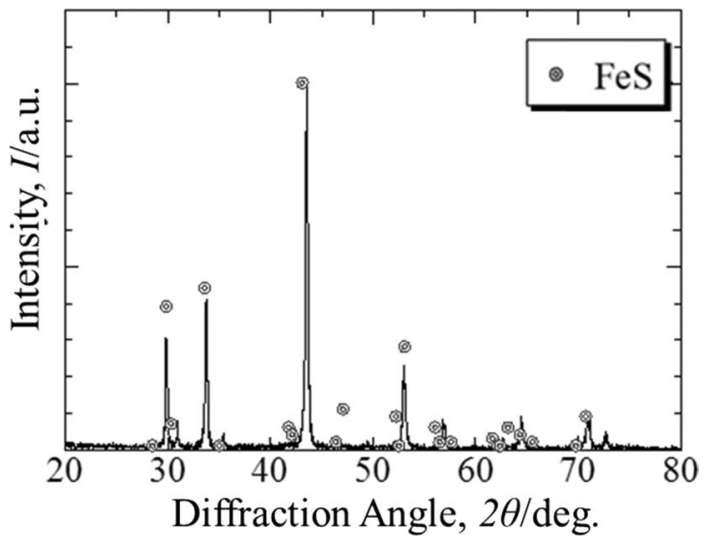

(b) XRD pattern

Fig. 4 SEM image and XRD pattern of FeS after sintering. 
結体は目立った気孔は確認されず，ほぼ緻密化していること がわかった。

Fig. 5 に FeS 焼結温度とかさ密度の関係を示す。焼結温度 の上昇とともにかさ密度も上昇し, $900^{\circ} \mathrm{C}$ で $4.62 \mathrm{~g} \cdot \mathrm{cm}^{-3}$ に達 していた，研摩した焼結体は，金属光沢を示していることが わかった. Fig. 6 に $900^{\circ} \mathrm{C}$ で焼結し, 研摩を施した後の FeS 焼 結体外観写真を示す.

ボールミル粉碳後の $\mathrm{FeS}$ 粉末と, 焼結後の $\mathrm{FeS}$ の化学量論 組成を検討した．前出の Fig. 2 の方法で行い，ボールミル粉 确後(燒結前)の $\mathrm{FeS}$ 粉末では, $\mathrm{Fe}: \mathrm{S}=0.89: 1$ となった。同 様に焼結後のものでは, $\mathrm{Fe}: \mathrm{S}=0.93: 1$ となり, 焼結後に $\mathrm{S}$ 成分の減少が確認された。

Table 1 は FeS 焼結体と関係する材料の室温での機械的諸 特性をまとめたものである. FeS 焼結体のビッカース硬さは $\mathrm{HV} 190$ ，破壊勒性值 $K_{\mathrm{IC}}$ は $1.1 \mathrm{MPa} \cdot \mathrm{m}^{1 / 2}$ となった。それぞれ の值は，鋼の酸化皮膜の主成分である $\mathrm{FeO}^{27)}$ のビッカース硬 さ $\mathrm{HV} 400$, 破壊勒性值 $K_{\mathrm{IC}} 1.5 \mathrm{MPa} \cdot \mathrm{m}^{1 / 2}$ と比較しても低い值 を示した。

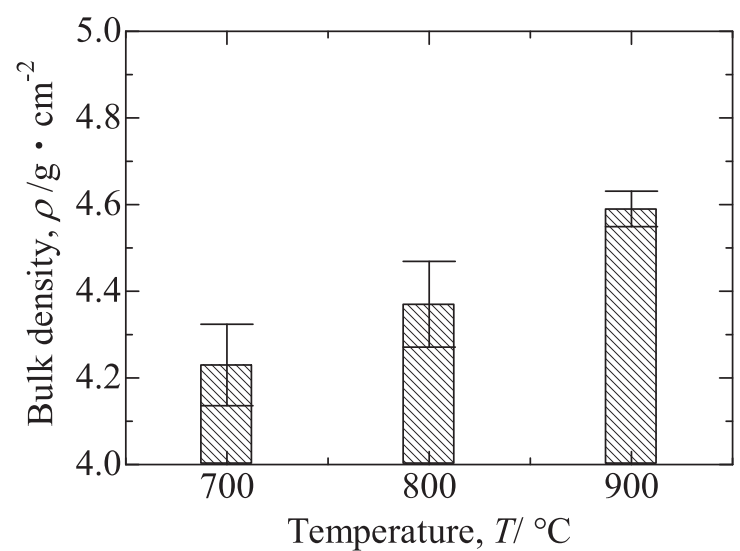

Fig. 5 Relationship between sintering temperature and density of FeS after sintering.

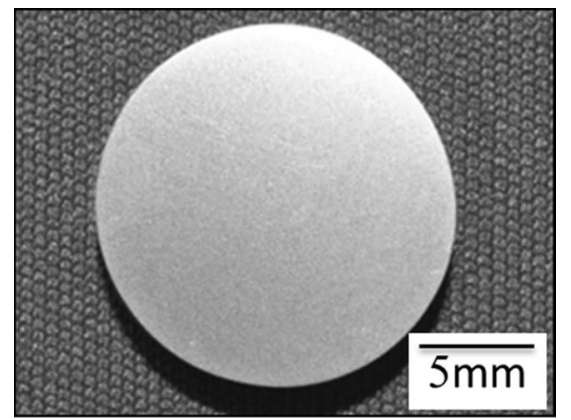

Fig. 6 Bulk FeS sintered at $900^{\circ} \mathrm{C}$ after polishing.

Table 1 Mechanical properties of sintered $\mathrm{FeS}$ and other $\mathrm{Fe}$ materials.

\begin{tabular}{llll}
\hline & $\begin{array}{l}\text { Density, } \\
\rho / \mathrm{g}^{\circ} \mathrm{cm}^{-3}\end{array}$ & $\begin{array}{l}\text { Vickers Hardness, } \\
H V\end{array}$ & $\begin{array}{l}\text { Fracture toughness, } \\
\text { KI } / \mathrm{MPa} \cdot \mathrm{m}^{1 / 2}\end{array}$ \\
\hline $\mathrm{FeS}$ & 4.62 & 190 & 1.1 \\
$\mathrm{Fe}(\mathrm{S} 55 \mathrm{C})$ & 7.86 & 241 & - \\
$\mathrm{FeO}$ & 5.46 & 400 & 1.5 \\
\hline
\end{tabular}

\section{4. 考察}

本研究では PECS による FeS 焼結体の緻密体の作製を行っ た．その結果， $900^{\circ} \mathrm{C} ， 45 \mathrm{MPa}$ でほぼ緻密化できることがわ かった，その際に焼結前後で $\mathrm{S}$ 成分が減少したことを確認し た。これはPECSによって FeSの S 成分が揮発したものと考 えられる. Pearsonによれば28), FeSの密度は, S 成分の増加 に伴い，減少することが報告されている，したがって本焼結 体の理論密度を求めるには FeS 中の S 成分を知る必要がある. この化学量論組成のモル比を改め直すと Fe : S= 48.3 : 51.7 と なる.Pearsonの報告をもとに今回の $\mathrm{FeS}$ 焼結体の理論密度

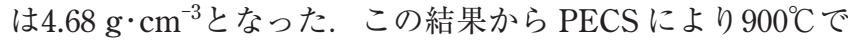
焼結した FeS は98.7\%の相対密度となり，十分に緻密なもの を得られることがわかった。ここで, PECS 前の FeS 粉末の 化学量論組成の初期值 $\mathrm{Fe}_{0.89} \mathrm{~S}(\mathrm{Fe}: \mathrm{S}=0.89: 1)$ は PECS 後に $\mathrm{Fe}_{0.93} \mathrm{~S}(\mathrm{Fe}: \mathrm{S}=0.93: 1)$ と変化したが, PECSによる $\mathrm{S}$ 成分 の減少はそれほど大きくないので, S 成分の制御を S P Fe を 加えることによってコントロールすることも可能であると考 えられる

PECS による焼結において, 焼結体の試料中心部と外周部 の温度差が発生することが報告されている29,30). 今回の $\mathrm{FeS}$ 焼結体に関しても硬さや粒径の分布を調査をしたが，有意な 差は確認できなかった。 今回の $\mathrm{FeS}$ 焼結は, 試料中心部と外 周部での顕著な温度差が現れる大きさではなかったものと考 えられる。

また, FeS 焼結体の常温でのビッカース硬さ, 破壊勒性值 は鍛造時に使用される金型鋼, 鍛造材料, 熱間銓造時に銓造 材料を覆う酸化皮膜と比較して低いことがわかる. FeS が金 型表面に存在する場合, 軟らかい FeS が硬い窒化層を保護し て摩耗させずに，金型とワークの材料間の潤滑剤としての役 割を果たすものと考えられる.

\section{5. 結 論}

本研究では鍛造金型の表面処理のひとつである浸硫窒化処 理を構成する硫化物層の主たる物質である FeS $\mathrm{PECS} に よ$ り緻密なバルク体を作製することに成功し, 機械的特性の評 価を行った。

ボールミル等で微細化した FeS 粉末の PECS により, 温度 $900^{\circ} \mathrm{C}$, 圧力 $45 \mathrm{MPa}$ の焼結条件で緻密な焼結体が得られた. PECS による FeS の焼結では焼結前後の化学量論組成の S 成 分が $\mathrm{Fe}_{0.89} \mathrm{~S}$ から $\mathrm{Fe}_{0.93} \mathrm{~S}$ へわずかに減少した. $\mathrm{FeS}$ 焼結体の ビッカース硬さ，破壊勒性值は銓造時に関連する材料のそれ よりは低いことがわかった.

本研究成果の一部は, 総合科学技術・イノベーション会議 の「SIP(戦略的イノベーション創造プログラム)/革新的設計 生産技術」(管理法人：NEDO）によって実施されたものであ る. 関係各位に深く感謝申し上げます。 
文献

1) Jpn. Soc. Tech. Plasticity: Handbook of Technology of Plasticity, Corona Publishing, Tokyo, 2006) pp. 230-231.

2) Jpn. Soc. Tech. Plasticity: Fundamentals in Plastic Working, (Corona Publishing, Tokyo, 2007) pp. 115-120.

3) K. Sakai: J. Jpn. Soc. Tech. Plasticity 19(1978) 1036-1043.

4) Sokeizai Center: Sokeizai (Sokeizai Center, Tokyo, 2016) pp. 40-48.

5) H. Yamamoto: J. Jpn. Soc. Tech. Plasticity 46(2005) 709-715.

6) O. Kato: Fujico Technical Report 3(1995) 34-38.

7) T. Nakamura, K. Kato and N. Matsui: Trans. JSME 52 (1986) 163-172.

8) Y. Tsuchiya: R\&D Review of Toyota CRDL 34(1999) 3-12.

9) K. Nishiyama, K. Taguchi, T. Ohdaira, M. Abe, K. Tashiro and T. Suzuki: J. Jpn. Soc. Powder Powder Metallurgy 41 (1993) 613-616.

10) N. Ikeda: Denki-Seiko 85(2014) 29-37.

11) S. Fujiki: J. Surf. Finishing Soc. Jpn. 52(2001) 535-539.

12) W. Hai-Dou, Z. Da-Ming, W. Kun-Lin and L. Jia-Jun: J. Mater. Sci. Lett. 22(2002) 1043-1046.

13) I. Lee and I. Park: Surf. Coating Technol. 200 (2006) 3540-3543.

14) O. Momose and S. Uchida: J. Met. Finishing Soc. Jpn. 26 (1975) $278-282$.

15) O. Momose and S. Uchida: J. Met. Finishing Soc. Jpn. 27 (1976)
447-450.

16) O. Momose and S. Uchida: J. Japan Inst. Metals 43(1979) 18-22.

17) O. Momose and S. Uchida: J. Japan Inst. Metals 45(1981) 718722 .

18) O. Momose and S. Uchida: J. Met. Finishing Soc. Jpn. 33(1982) 152-155.

19) Sokeizai Center: Sokeizai (Sokeizai Center, Tokyo, 2014) p. 32.

20) S. Ogawa: Machine Design 44(2000) 38.

21) O. Yanagisawa, H. Hatayama and K. Matsugi: Materia Japan 33 (1994) 1489-1496.

22) K. Kakegawa: J. Soc. Inorg. Mater. Jpn. 13(2006) 157-164.

23) T. Sever, M. Kržmanc, S. Bernik, D. Suvorov and B. Jančar: Mater. Design 114(2017) 642-651.

24) S. Harish, D. Sivaprahasam and M. Battabyal: J. Alloy. Compd. 667 (2016) 323-328.

25) Y. Tang, Z. Ge and J. Feng: Crystals 7(2017) 141-150.

26) T. Tsukahara, N. Takata, S. Kobayashi and M. Takeyama: Tetsuto-Hagané 102(2016) 29-35.

27) M. Nanko: Form Tech Review 19(2010) 52-55.

28) W. B. Pearson: A Handbook of Lattice Spacings and Structures of Metals and Alloys 2,(Pergamon Press, London, 1967) pp. 74-75.

29) H. Tomino, H. Watanabe and Y. Kondo: J. Jpn. Soc. Powder Powder Metallurgy 44(1997) 974-979.

30) M. Nanko, T. Maruyama and H. Tomino: J. Japan Inst. Metals 63(1999) 917-923. 